\title{
Surgical correction of isolated persistent left superior vena cava draining to left atrium in a neonate
}

\author{
YVONNE D L SIBLEY, KEITH D ROBERTS, ERIC D SILOVE \\ From the Children's Hospital, Birmingham
}

SUMMARY A one day old baby who presented with cyanosis was later shown to have an isolated persistent left superior vena cava draining into the left atrium with hypoplastic right superior vena cava. This extremely rare anomaly was diagnosed by cardiac catheterisation at one week. Surgical correction at two weeks, by anastomosis of the innominate vein to the right atrium and by ligation of the left superior vena cava at its junction with the left atrium, was successful. This patient is the youngest case in which successful surgical correction of this isolated anomaly has been reported.

Persistent left superior vena cava with hypoplastic or atretic segment of the right superior vena cava is a rare anomaly-there are only 73 reported cases. ${ }^{12}$ In most reports either the persistent left superior vena cava drained into the coronary sinus or there were other associated cardiac anomalies. ${ }^{134} \mathrm{~A}$ persistent left superior vena cava draining into the left atrium with a hypoplastic or atretic segment of the right superior vena cava and no other cardiac anomaly is an extremely rare finding. We report a patient who presented early in the neonatal period with this anomaly and in whom early surgical correction was successful.

\section{Case report}

A male infant, born at 41 weeks' gestation and weighing $3.07 \mathrm{~kg}$, presented at the age of 28 hours with cyanosis. On examination he was mildly cyanosed in air, with no tachypnoea or rib recession. He had normal pulses, normal heart sounds, and no heart murmurs. Arterial oxygen tension was $5.53 \mathrm{kPa}$ in air and $5.22 \mathrm{kPa}$ in $80 \%$ oxygen. The chest radiograph showed cardiomegaly with a globular heart and normal lung vascularity. The electrocardiogram was normal. The echocardiogram was thought to show a normal heart but there was a suspicion of a venous channel behind the left atrium that was thought to be a persistent left superior vena cava draining into the coronary sinus or an anoma-

Requests for reprints to Dr Yvonne D L Sibley, The Children's Hospital, Ladywood Middleway, Birmingham B16 8ET. lous pulmonary venous channel.

At the age of six days cardiac catheterisation was performed because of persisting cyanosis. It showed a right to left shunt at the atrial level. Angiography showed a large left superior vena cava draining into the left atrium with a severely hypoplastic right superior vena cava draining to the right atrium. A repeat echocardiogram after catheterisation confirmed the persistent left superior vena cava draining into left atrium (Figure).

Surgical correction was undertaken at the age of two weeks. The infant was surface cooled to $32^{\circ} \mathrm{C}$ and the chest was opened via a median sternotomy. A large left superior vena cava was found to be draining into the cephalad aspect of the left atrium. The right internal jugular vein drained into a large innominate vein which was connected to the left superior vena cava. The right superior vena cava draining into the right atrium was very small. The innominate vein was detached from the right superior vena cava near its junction and was anastomosed to the right atrial appendage. The left superior vena cava was ligated at its junction with the left atrium. Cardiopulmonary bypass was not required. The patient was ventilated for two days after operation and made an uneventful recovery.

Contrast echocardiography performed six days after operation showed drainage of the left superior vena cava via the innominate vein into the right atrium, with no contrast entering the left atrium. On review as an outpatient at the age of five months he was thriving, not cyanosed, and had no heart murmurs. 

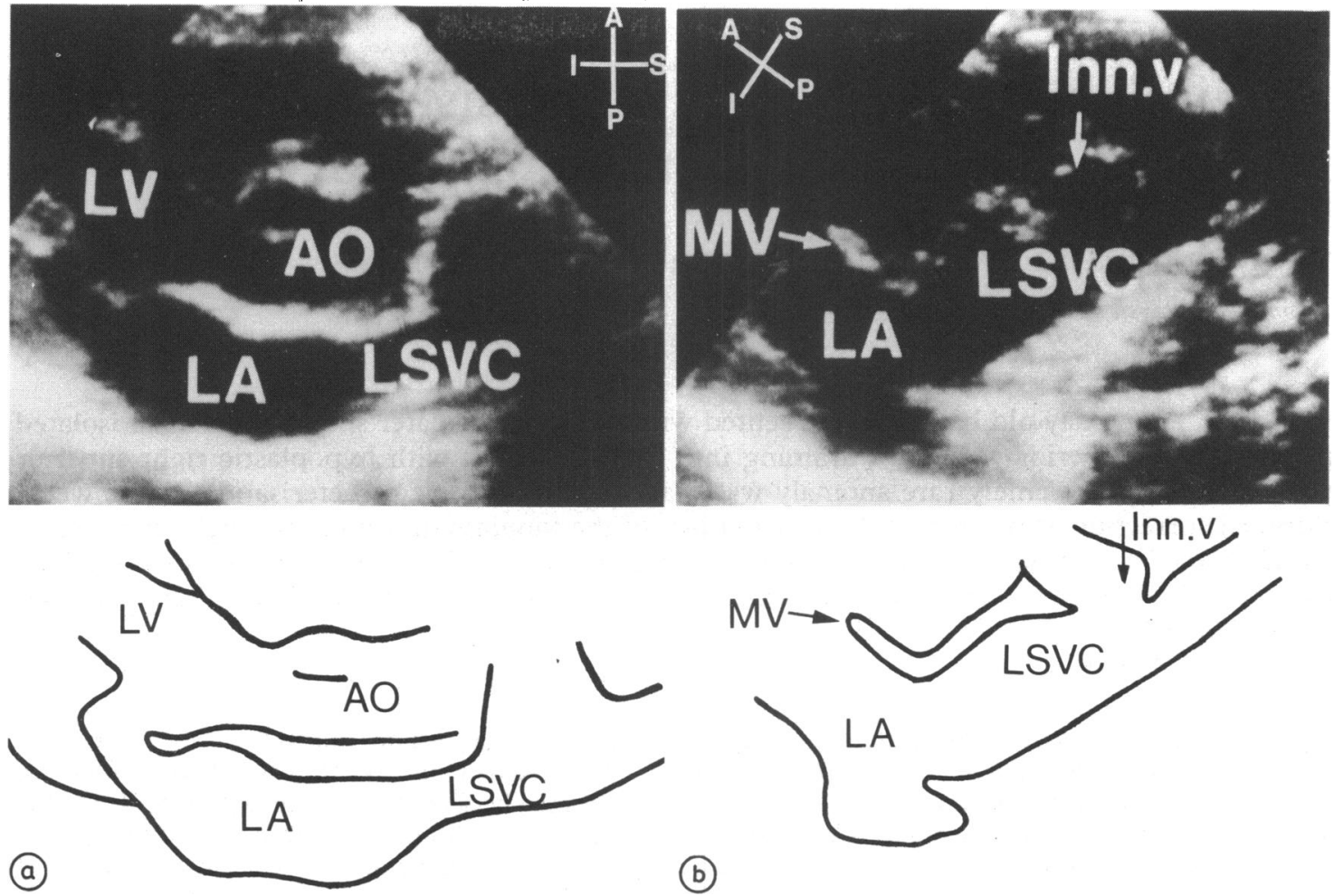

Figure Preoperative echocardiograms. (a) Long axis left parasternal view showing left superior vena cava (LSVC) draining into left atrium (LA). (b) Anticlockwise rotation of long axis left parasternal view to demonstrate junction of innominate vein (Inn v) and left superior vena cava. $L V$, left ventricle; $A O$, aorta; $L A$, left atrium; $M V$, mitral valve.

\section{Discussion}

Foale et al reported the recognition of anomalous systemic venous return using cross sectional contrast echocardiography. ${ }^{5}$ When echocardiography suggests the presence of a venous channel behind the left atrium the differential diagnosis is usually a persistent left superior vena cava draining to the coronary sinus or total anomalous pulmonary venous drainage. In this case the pulmonary veins clearly drained into the left atrium and contrast echocardiography would have defined the drainage of the left superior vena cava. After operation contrast echocardiography was useful in demonstrating the successful surgical correction of the anomaly. In total anomalous pulmonary venous drainage the venous channel would not be opacified by contrast.

Early surgical correction was undertaken because of the large right to left shunt from the persistent left superior vena cava to the left atrium. Because of the favourable anatomy cardiopulmonary bypass was not required for correction. A persistent left superior vena cava draining into left atrium without other cardiac malformations is extremely rare and this is the youngest patient reported to have had successful surgical correction of this anomaly.

\section{References}

1 Pugliese P, Murzi B, Aliboni M, Eufrate S. Absent right superior vena cava and persistent left superior vena cava. Clinical and surgical considerations. $\mathcal{f}$ Cardiovasc Surg (Torino) 1984; 25: 134-7.

2 Karnegis JW, Wang Y, Winchell P, Edwards JE. Persistent left superior vena cava, fibrous remnant of the right superior vena cava and ventricular septal defect. Am $\mathcal{f}$ Cardiol 1964; 14: 573-7.

3 Bjerregaard P, Lawson HB. Persistent left superior vena cava. Acta Paediatr Scand 1980; 69: 105-8.

4 Lennox CC, Zuberbuhler JR, Park SC, et al. Absent right superior vena cava with persistent left superior vena cava: implications and management. Am $\mathcal{F}$ Cardiol 1980; 45: 117-22.

5 Foale R, Bourdillon PD, Somerville J, Rickards A. Anomalous systemic venous return: recognition by two-dimensional echocardiography. Eur Heart $\mathcal{f} 1983$; 4: 186-95. 